\begin{abstract}
$\mathbf{A} \mathbf{C}_{\mathrm{ASE}} \mathbf{S}_{\mathrm{TUdy}}$
FOOD SCIENCE.

RESEARCH JOURNAL

e ISSN-2230-9403 - Visit us : www.researchjournal.co.in

Volume 6 | Issue 2 | October, 2015 | 412-417

DOI : $10.15740 / \mathrm{HAS} / \mathrm{FSRJ} / 6.2 / 412-417$
\end{abstract}

\title{
To study the impact of dietary habits and nutritional intake on the behaviour of the adolescents
}

\author{
Ritu Garg And Varsha Goel
}

\begin{abstract}
Present study was conducted to know the dietary habits and nutritional intake of the adolescents. The present study critically examines different dimensions of health, nutrition and socio-psycho behaviour of both rural and urban adolescents of Ghaziabad. The suggestions of the study demand interventions to be initiated by Government, parents, teachers, NGOs, academic institutes and newline health workers. Adolescence is a period between childhood and adulthood during which the individual learns the skills needed to flourish as an adult. Although adolescence begins with the biological series of events called puberty, some authors suggest that adolescence was culturally invented during the last century and defined it as a period in which the individual could gain the newline complex skills necessary to navigate adulthood in a Western culture. Newline Puberty, the beginning of adolescence, is marked by dramatic physical changes in both growth rate and sexual characteristics (Glucksberg and Darly, 1980; Field, 1995).Study was carried out on 1500 adolescents ( 750 boys and 750 girls) from Ghaziabad. The results show that some of the adolescents lag behind the standard weight and height. Most of the adolescent were found to have one or more than one medical problems at present and in the past also. The diet of adolescent were lacking in most of nutrients with some specific nutritional deficiencies seen in the sample. The psychosocial behaviour of adolescents shows that they have few behavioral problems and indulge in uncivilized and unhealthy addictions like smoking and substance abuse.
\end{abstract}

Key Words : Nutrition, Health, Adolescence

How to cite this article : Garg, Ritu and Goel, Varsha (2015). To study the impact of dietary habits and nutritional intake on the behaviour of the adolescents. Food Sci. Res. J., 6(2): 412-417.

RITU GARG, Shri Ram College, MUZAFFARNAGAR (U.P.) INDIA

Associate Authors'

VARSHA GOEL, Shri Ram College, MUZAFFARNAGAR (U.P.) INDIA 